\title{
探月工程三期月地高速再入返回飞行器防热系统 设计与验证
}

董彦芝 ${ }^{(1)}$ ，刘峰 ${ }^{(1)}$, 杨昌吴 ${ }^{(1)}$, 张高 ${ }^{(1)}$, 赵建设 ${ }^{(2)}$, 罗晓光 ${ }^{(3)}$, 欧东斌 ${ }^{(3)}$, 梁馨 ${ }^{(2)}$, 郭梅梅 $^{(2)}$,马涁 ${ }^{(1)}$, 逯运通 ${ }^{(1)}$

(1) 中国空间技术研究院总体设计部，北京 100094;

(2) 航天材料及工艺研究所, 北京 100076;

(3) 中国航天空气动力技术研究院, 北京 100074

*E-mail: dongyanzhi_good@163.com

收稿日期: 2014-12-06; 接受日期: 2014-12-27

国家中长期科技发展规划重大专项资助项目

摘要本文针对月地高速再入返回的高焓、二次大气层再入、高热流密度峰值与长加热 时间耦合的气动加热环境特点, 提出了飞行器防热系统设计方案, 研制了七种新型碳硅复 合烧蚀防热材料, 建立了防热系统分析模型, 并完成了地面试验验证. 经对飞行试验数据的 详细分析, 结果表明防热系统的实际性能与设计预期一致.

关键词

月地返回

烧蚀

防热系统

设计

验证

\section{1 引言}

防热系统是月地高速再入返回飞行器的关键系 统, 为返回器以 $11 \mathrm{~km} / \mathrm{s}$ 的再入速度、二次大气层再 入的安全返回提供保证.

月地高速再入返回飞行器的再入初始速度接近 第二宇宙速度, 与近地轨道返回相比, 对飞行器防热 系统提出了许多新的挑战. 经过论证, 我国已有的防 热材料和防热系统无法满足月地高速再入返回飞行 器对防隔热、轻量化、烧蚀外形等方面的综合要求; 对防热材料在高焓、跳跃式再入环境下的烧蚀机理和 地面模拟试验方法也未曾开展过相关研究. 因此, 必 须研制全新的月地高速再入返回飞行器防热系统.

烧蚀防热可以适应宽幅突变热流环境，安全性
和可靠性高 ${ }^{[1,2]}$. 调研国内外防热技术发展趋势, 烧 蚀防热技术仍然是解决再入高热流密度峰值、大总加 热量的首选，如美国猎户座飞船和俄罗斯快船号，均 采用了烧蚀防热设计方案 ${ }^{[3,4]}$. 我国在神舟飞船、返回 式卫星和导弹任务中建立了完整的烧蚀防热结构研 制配套体系. 因此, 月地高速再入返回飞行器防热系 统采用烧蚀防热方案，并开展系统性的设计与验证 工作.

\section{2 技术难点}

1) 与近地轨道返回相比, 月球再入返回过程中 的气动力、热环境更加严酷.

月地高速再入返回速度接近第二宇宙速度，再

引用格式: 董彦芝, 刘峰, 杨昌吴, 等. 探月工程三期月地高速再入返回飞行器防热系统设计与验证. 中国科学: 技术科学, 2015, 45: 151-159 Dong Y Z, Liu F, Yang C H, et al. Design and verification of the TPS of the circumlunar free return and reentry flight vehicle for the 3rd phase of Chinese lunar exploration program (in Chinese). Sci Sin Tech, 2015, 45: 151-159, doi: 10.1360/N092014-00468 
入高度 $120 \mathrm{~km}$, 半弹道式再入条件下的热流密度峰 值达到飞船的 4 倍、返回式卫星的 1.7 倍; 弹道式再 入条件下的热流密度峰值达到飞船的 7.5 倍、返回式 卫星的 3.2 倍; 标称条件下的气动剪力则是飞船的 5.2 倍. 可见, 较近地轨道返回, 月球返回时烧蚀与 气流冲刷更为严重, 要求防热材料必须具有更好的 防热与耐气流冲刷能力. 此外, 月球再入返回时大气 的总比焓较飞船增大约 2 倍, 会对防热材料的烧蚀机 理产生显著的影响.

2) 半弹道跳跃式再入方式对防热系统的结构性 能要求更高.

与直接再入有所不同, 月地高速再入返回任务 采用半弹道跳跃式再入方式, 不仅气动加热时间长, 二次加热还会导致热冲击. 气动加热时间长要求防 热结构必须具有更优异的隔热性能, 而热冲击过程 中要防止防热层出现开裂.

3) 月球轨道空间环境与近地轨道空间环境相比, 条件更为恶劣, 防热结构的最低温度可达 $-120^{\circ} \mathrm{C}$, 对 材料和结构的空间环境适应性提出了更高的要求.

4) 轻量化是衡量高品质航天产品的首要指标, 而深空探测任务对防热系统的轻量化要求更高.

返回器外形包络为飞船返回舱的 $1 / 2$, 面积比为 $1 / 4$, 结构质量比应为 $1 / 4$. 而返回器结构质量却仅为 飞船返回舱的 $14 \%$, 即在气动力、热环境更加严酷的 情况下, 返回器的防热系统重量占比却要更小. 飞行 器返回器与飞船返回舱的技术指标对比如表 1 所示.

5) 返回器尺度小, 质心和气动外形变化对气动 力影响大, 对烧蚀外形控制要求更高, 尤其是高热 流、小半径的大底拐角.

6) 我国已有的防热材料体系无法满足防热、隔 热与轻量化综合要求.
导弹材料密度高、耐受短时高热流密度环境的能 力强, 但导热系数大, 隔热性能差, 不适用于长时间 加热; 飞船材料密度较低、隔热性能好, 但不能耐受 高热流密度的烧蚀与冲刷. 因此需要研制具有良好 防隔热性能的新型低密度和超低密度防热材料.

7) 我国未掌握高焓和跳跃式再入气动加热环境 下防热材料的烧蚀机理和地面试验方法.

我国返回式卫星由近地轨道返回, 采用弹道式 直接再入方式. 神舟飞船同样由近地轨道返回, 采用 半弹道直接再入方式. 我国未实施过深空跳跃式再 入任务, 也未对高焓、跳跃式再入环境下的材料烧蚀 机理和地面模拟试验方法开展过相关研究.

\section{3 技术方案}

\section{1 整器防热设计}

月地高速再入返回器采用钟罩式气动外形, 返 回器结构分为可拆装的 4 大部件: 前端、侧壁、大梁 和大底. 其中大梁置于器内, 用于承载单机设备; 前 端、侧壁和大底均为承力-防热复合式结构, 内部为铝 合金承力结构, 外部粘接防热结构. 前端和侧壁的防 热结构包括迎风面蜂窝增强低密度烧蚀材料、背风面 蜂窝增强低密度烧蚀材料、开口边缘防热环和开口舱 盖; 大底防热结构包括拐角环、迎风面蜂窝增强低密 度烧蚀材料和背风面蜂窝增强低密度烧蚀材料.

为减轻结构重量, 针对返回器表面各处的热流 环境特点, 提出了分区域、变材料、变厚度的轻量化 设计方案, 即充分利用各种防热材料的最佳应用温 度范围, 在大底与侧壁、迎风面与背风面处分别采取 适用的防热材料、布局方式和防热层厚度设计.

\section{表 $1 飞$ 飞行器返回器与神舟飞船返回舱的技术指标对比}

\begin{tabular}{|c|c|c|c|}
\hline 技术指标项目 & 神舟飞船返回舱 & 飞行器返回器 & 比例关系(返回器/返回舱) \\
\hline 再入方式 & 半弹道直接再入 & 半弹道跳跃式再入 & 1 \\
\hline 气动外形(mm) & $\Phi 2517 \times 2500$ & $\Phi 1258 \times 1236$ & $L: 1 / 2 ; S: 1 / 4$ \\
\hline 结构重量指标(kg) & 1300 & 182 & $14 \%$ \\
\hline 防热系统重量指标(kg) & 580 & 122 & $21 \%$ \\
\hline 热流密度峰值 $\left(\mathrm{MW} / \mathrm{m}^{2}\right)$ & 1.31(拐角位置) & 5.2(拐角位置) & 4 \\
\hline 加热时间(s) & 530 & 1050 & 2 \\
\hline 总加热量 $\left(\mathrm{MJ} / \mathrm{m}^{2}\right)$ & 321.3(拐角位置) & 715(拐角位置) & 2.2(拐角位置) \\
\hline 气动剪力 $(\mathrm{Pa})$ & 正常返回最大 44.7 高空逃逸最大 65.1 & 最大 340 & 5.2 \\
\hline 再入最大过载(g) & 4 & 7 & 1.7 \\
\hline 气体总比焓 $(\mathrm{MJ} / \mathrm{kg})$ & 29 & 57 & 2 \\
\hline
\end{tabular}


采取上述轻量化设计方案, 防热系统既能够满 足苛刻的热环境要求, 又能够满足返回器的质心配 置要求.

为保证再入过程中返回器能够维持光滑气动外 形, 提出了材料密度梯度配置、相邻材料烧蚀速率全 轨道动态匹配的设计方案, 要求不同材料交界面处 的烧蚀和隔热性能具有良好的匹配性、再入过程中不 产生烧蚀台阶、结构内壁的温升均匀, 达到最优的减 重效果.

对于承受高热流、大剪力的大底拐角区域, 采用 连续纤维增强、顺气流排布拐角环设计方案, 提高其 耐烧蚀剥蚀能力, 维持拐角气动外形.

为解决地面成型过程和在轨服役时侧壁与大底 的热变形匹配难题, 对各开口边缘防热环和拐角环 的线胀性能进行了调控, 同时采用弹性较好的硅橡 胶进行常温固化胶接, 并严格控制胶层厚度、成型温 度等关键要素, 效果良好.

整器防热设计如表 2, 图 1 和 2 所示.

\section{2 局部防热设计}

局部防热设计同样是防热系统的研制重点, 要

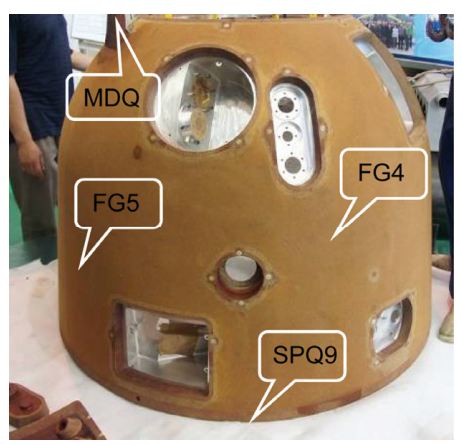

图 1 侧壁防热结构

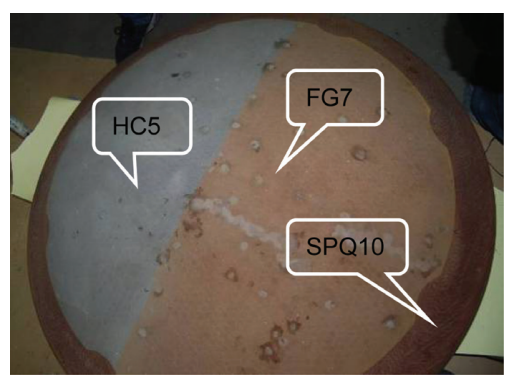

图 2 大底防热结构

确保各部位的烧蚀状态不会影响气动外形、不产生明 显的热流扰动, 缝隙和突起处不出现过热、窝火问题.

需要开展局部防热设计的部位包括：前端单向 泄压阀开孔、前端压紧机构(突起物)、各安装螺钉孔 处防热螺塞、各姿控发动机舱盖(含导流管)、伞舱盖 稳定翼(突起物)、伞舱盖安装缝隙、伞舱盖弹射器、 电分离板电连接插座及杆件(突起物)、天线舱盖安装 缝隙、天线舱盖抛盖锁、压力高度控制器开孔、环路 热管放气口、钛管(突起物)、大底分离垫块(凹坑)等. 通过对当地热流环境条件和结构形式特点的分 析，在各部位采用具有针对性的防热设计.

钛管属于高热流区的突起物结构, 采取再入段 初期尽早烧去的设计方案, 并确保烧平后的残留结 构对气动加热扰动降至最低; 大底分离垫块属于高 热流区的凹坑结构, 因此将凹坑深度较浅的一侧设 置在迎风面, 减少其对气动加热的扰动; 通过构型布 局设计, 将其他突起物、开口放置在热流较低、气动 压力较小部位, 以减小突起物和开口对局部热流的 干扰，并对当地单机设备采取相应的防隔热措施.

伞舱盖装配缝隙采用密封圈实现热密封, 并利 用设计手段保证密封圈位置的温度不超过使用温度; 由于功能需要, 弹抛天线舱盖的器表装配㖓隙不能 进行封堵, 因此采用硅橡胶对天线舱内进行热密封,

表 2 整器防热设计

\begin{tabular}{|c|c|c|c|c|}
\hline 部位 & 部件 & \multicolumn{2}{|c|}{ 结构形式 } & 防热层厚度 \\
\hline 前端 & 前端盖 & \multicolumn{2}{|c|}{ SPQ9 边缘防热环+FG4 大面积防热层 } & 等厚度设计 \\
\hline \multirow[b]{2}{*}{ 侧壁 } & 大面积 & $\begin{array}{c}\text { 迎风面 } 120^{\circ} \sim 240^{\circ} \text { 范围 } \\
\text { 其他位置 }\end{array}$ & $\begin{array}{l}\text { FG5 材料, } \\
\text { FG4 材料 }\end{array}$ & \multirow[b]{2}{*}{ 轴向变厚度设计 } \\
\hline & $\begin{array}{c}\text { 伞舱盖 } \\
\text { 防热环及舱盖 } \\
\text { 稳定翼 }\end{array}$ & \multicolumn{2}{|c|}{$\begin{array}{c}\text { SPQ9 边缘防热环+FG5 大面积防热层 } \\
\text { SPQ9 材料 }\end{array}$} & \\
\hline \multirow[b]{2}{*}{ 大底 } & 拐角 & & & \\
\hline & 大面积 & $\begin{array}{l}\text { 迎风 } 180^{\circ} \text { 区域 } \\
\text { 背风 } 180^{\circ} \text { 区域 }\end{array}$ & $\begin{array}{l}\text { FG7 材料 } \\
\text { HC5 材料 }\end{array}$ & 偏轴变厚度设计 \\
\hline
\end{tabular}


并通过试验与定量分析计算出热气进入的影响; 其 余缝隙防热主要采用防火填料进行处理, 并开展了 防火填料烧蚀试验予以验证.

\section{3 新型碳硅复合低密度烧蚀防热材料研制}

1) 新型碳硅复合蜂窝增强低密度烧蚀材料

该类新型防热材料采用硅碳混合的材料设计方 法, 其中碳基起到高温抗烧蚀和增加碳层强度的作 用，硅基起到高温下发生熔融、吸收部分热量、同时 减少碳基与氧气的接触、降低碳基氧化后退和收缩的 作用. 新研的硅碳复合蜂窝增强低密度烧蚀防热材 料充分利用碳基元素与硅基元素的不同优势，结合 C-Si-O 体系密度设计与调控技术和多组元多尺度均 匀复合技术, 彻底解决了气动加热及轻质化的难题.

该材料技术应用于大底大面积防热材料 FG7, HC5 和侧壁大面积防热材料 FG5, FG4.

2) 新型混杂连续纤维增强轻质烧蚀材料

该类新型防热材料使用石英纤维、玻璃纤维及可 分解纤维三元长纤维组成的 SPQ 纤维布增强体系. 其中耐高温的石英纤维作为支撑骨架用于抵御第一 次再入时的短时高热流密度条件的冲刷; 低熔点的 玻璃纤维用作第二次再入时的长时间低热流密度条 件下的熔融粘合剂, 维持碳层稳定; 可分解纤维在整 个烧蚀过程参与复合材料的烧蚀分解, 提高复合材 料的烧蚀分解防热效率.

为了降低材料密度, 将轻质填料引入到连续纤 维增强的预浸料中, 突破了连续纤维增强复合材料 中高含量轻质填料添加困难的难题, 解决了添加高 含量轻质填料后材料性能急剧下降的问题. 与神舟 飞船拐角环所用 MD2 材料相比，材料密度降低 $28 \%$ 以上，同时还提高了材料的烧蚀隔热性.

采用该新型混杂连续纤维增强轻质烧蚀材料的 大底拐角环为异型环状结构, 为保证拐角环的整体 结构性、强度以及在高热流密度、强气流冲刷下的抗 烧蚀剥蚀性能, 采用了螺旋立体铺覆成型工艺方案 (图 3), 其螺旋铺层方式同时大大降低了缝隙沿布层 扩展的概率, 提高了产品的可靠性.

\section{3) MDQ 材料}

侧壁稳定翼的结构形式不适合采用 SPQ 材料成 型, 因此在 MD2 材料中增加熔点较高的空心硅基纤 维并添加空心填料, 在提高材料烧蚀性能的同时进 一步降低材料密度, 并避免由于氧化反应而造成的
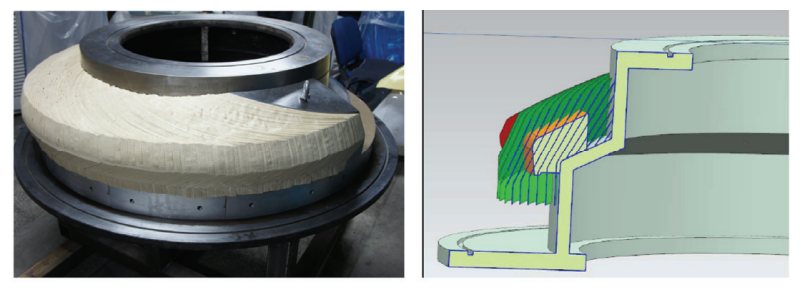

图 3 大底拐角环螺旋立体铺覆成型工艺

碳化收缩. 研制出的 MDQ 材料密度较 MD2 降低 $28 \%$.

\section{4 防热系统分析}

1) 烧蚀机理分析及性能预测评估

对不同防热材料在气动加热过程中的烧蚀响应、 表面形貌状态和炭化层构成(图 4)开展了详细的烧蚀 机理分析, 碳硅复合蜂窝增强低密度防热材料(HC5, FG4, FG5, FG7)兼具碳化热解类材料与硅基材料的 烧蚀行为, 传热耦合模型必须考虑热解炭化反应对 热响应的影响; 而 SPQ9, SPQ10 和 MDQ 材料的烧蚀 机理建模需要重点考虑液态层流失与树脂热解炭化 对表面能量平衡及炭化层性质的影响.

在烧蚀机理分析基础上, 提出了碳、硅体积加权 的整体烧蚀速率模拟方法, 解决了碳的氧化、硅的流 失等多物理化学机制作用下的烧蚀模拟问题, 建立 了碳-硅基复合材料在高焓二次加热环境下的烧蚀模 型, 形成了烧蚀-传热耦合分析通用计算方法, 拓展 了烧蚀模型对任意比例碳-硅元素组分防热材料的适 应性, 实现了新型防热材料烧蚀性能的准确预测与 评估.

\section{2) 高焓影响分析}

Apollo 研制过程中对高焓的影响进行了分析和 试验研究, 结果表明: 随着焓值的增加, 材料热解产

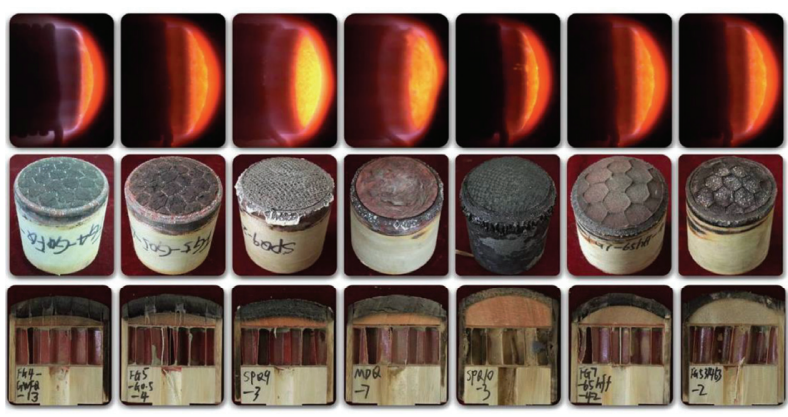

图 4 材料烧蚀试验 
生气体的热阻塞效应增强, 同时到达烧蚀材料表面 气体质量降低. 根据分析和试验得出了烧蚀速率随 焓值的变化规律见图 $5^{[5]}$.

返回器防热材料为兼具碳基和硅基特性的碳-硅 复合材料, 该材料体系与美国 Apollo 防热材料体系 类似, 因此高焓对防热材料的影响趋势也应该较为 一致. 基于上述分析, 返回器防热设计过程中, 采用 与 Apollo 类似的烧蚀分析模型:

$$
q_{\mathrm{N}}=\psi q_{\mathrm{or}}\left(1-\frac{h_{\mathrm{w}}}{h_{\mathrm{r}}}\right)-\varepsilon \sigma T_{\mathrm{w}}^{4}+\dot{m}_{\mathrm{C}} \Delta H_{\mathrm{C}},
$$

其中 $q_{\mathrm{N}}$ 为表面净热流; $\psi$ 为对流阻塞系数; $q_{\mathrm{or}}$ 为冷 壁热流; $h_{\mathrm{w}}$ 为壁面焓; $h_{\mathrm{r}}$ 为恢复焓; $\varepsilon$ 为壁面发射率; $T_{w}$ 为壁面温度; $\Delta H_{\mathrm{C}}$ 为碳的燃烧热.

$$
\dot{m}_{\mathrm{C}}=B^{\prime} \psi q_{\mathrm{or}} / h_{\mathrm{r}}, B^{\prime}=k B,
$$

其中 $\dot{m}_{\mathrm{C}}$ 为碳的质量损失率; $B$ 为无量纲烧蚀因子; $B^{\prime}$ 为修正后的无量纲烧蚀因子; $k$ 为无量纲烧蚀因 子修正系数.

\section{3) 二次加热影响分析}

为了考核二次加热对防热系统的影响, 防热材 料篮选与研制过程中开展了材料热冲击考核试验, 同时利用试验数据进行外推, 对防热结构的二次加 热影响进行了分析验证.

针对返回器跳跃式再入、二次加热的气动热环境 特点, 设计了两种地面烧蚀试验考核方法: (1) 首先 开展材料的第一次烧蚀试验, 模拟再入第一次加热; 试验完成温度降至室温后, 观察材料的烧蚀状态; 然 后, 再次开展材料的烧蚀试验, 模拟再入第二次加热; 试验后检查材料的烧蚀状态. (2) 采用多台阶轨道模

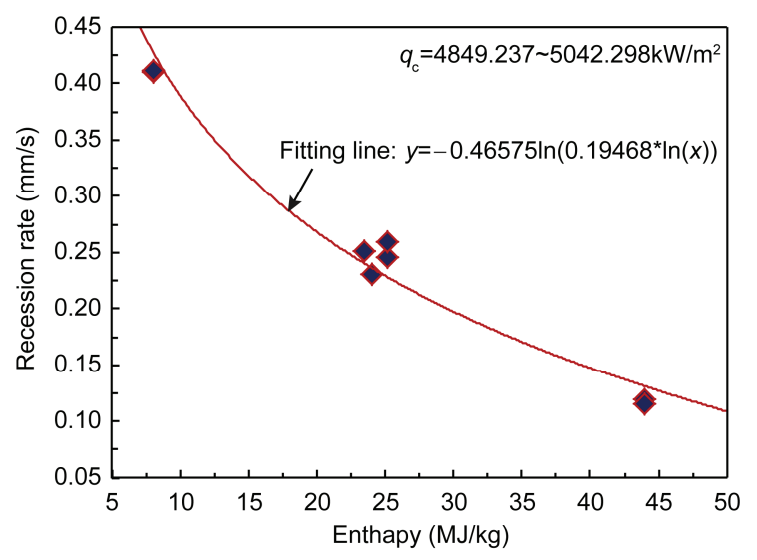

图 5 Apollo 高焓影响分析和试验结果
拟的烧蚀试验方法, 两次加热中间阶段电弧加热器 停车, 模拟返回器跳出大气层的状态.

试验结果表明, 防热材料通过两种形式的二次 加热试验, 表面烧蚀状态良好, 碳层结实完整, 未出 现开裂. 对于多台阶轨道模拟中间停车段, 防热材料 表面通过辐射向周围常温环境散热, 由于防热材料 表面温度仍能够达到 $700^{\circ} \mathrm{C}$ 量级, 经计算, 表面向常 温环境的辐射换热的热流密度, 与真实再入向空间 环境辐射换热的热流密度相差不大, 试验可反映真 实再入过程.

图 6 给出了再入过程驻点位置表面温度的分析 曲线, 在返回器跳出段, 防热结构表面温度下降, 但 仍不低于 $700^{\circ} \mathrm{C}$, 同时跳出段的降温速率低于第一次 加热的升/降温速率. 参考地面热冲击考核试验数据, 返回器防热材料和防热结构能够满足跳跃式再入、二 次加热的要求.

4) 对流加热与辐射加热共存影响分析

由于再入过程中迎风大底拐角附近存在较强的 辐射加热, 辐射加热对防热材料烧蚀性能的影响需 要进行重点分析. 采用将辐射加热项 $\left(q_{\text {radiation }}\right)$ 作为独 立热源并入防热材料净热流能量平衡公式的方法, 评估其对防热材料烧蚀性能及热响应的影响, 其表 达式为

$$
q_{\mathrm{N}}=\psi q_{\mathrm{or}}\left(1-\frac{h_{\mathrm{w}}}{h_{\mathrm{r}}}\right)-\varepsilon \sigma T_{\mathrm{w}}^{4}+\dot{m}_{\mathrm{C}} \Delta H_{\mathrm{C}}+q_{\text {radiation }},
$$

其中 $q_{\text {radiation }}$ 为辐射加热.

采用上述烧蚀模型对不同辐射加热条件下材料

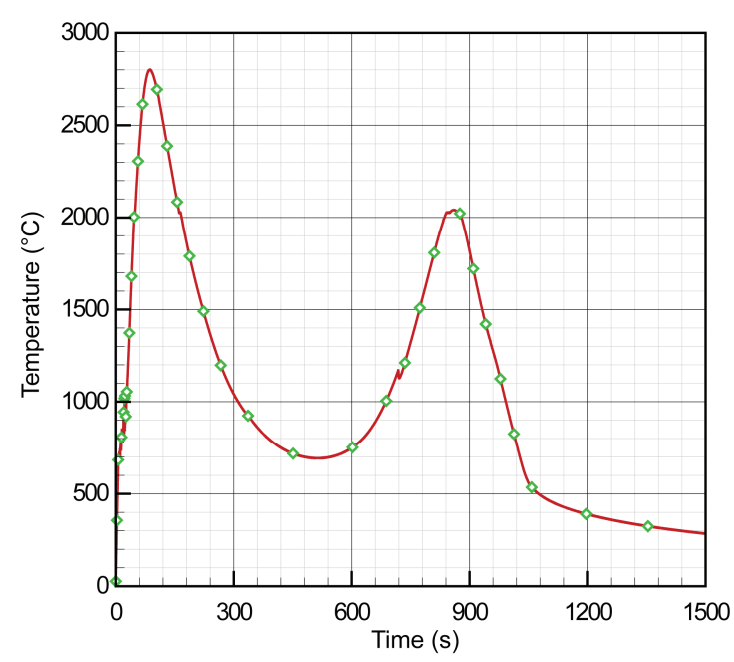

图 6 再入过程驻点位置表面温度分析结果 
的烧蚀行为进行计算, 综合来看, 辐射加热比例越高 材料烧蚀带走的热量越小, 防热材料的背温略微升 高. 在飞行返回轨道下, 辐射热流比例较小且加热时 间极短, 评估计算表明, 将辐射热流等效为对流热流 的处理方法对烧蚀量评估的误差不高于 $2 \%$, 对背温 热响应的误差不高于 $1 \%$.

因此, 在返回器防热结构温度响应预测计算和 地面试验时, 可以将辐射加热合并到对流加热中统 一考虑，无需单独考虑辐射加热.

\section{5) 温度场分析}

研制过程中, 采用数值仿真手段对防热系统开 展了详尽的分析验证工作, 见表 3. 分析结果表明, 返回器的防热设计全面满足结构背温指标要求.

\section{4 地面试验验证}

地面验证试验包括空间环境试验和烧蚀试验两 方面内容.

空间环境试验主要包括低温试验、热循环试验和 辐照试验. 其中, 低温试验考察防热材料耐受低温环 境的能力; 热循环试验考察返回器整器结构在空间
温度交变环境下的匹配性; 辐照试验考察防热材料 耐受带电粒子辐照的能力.

烧蚀试验主要包括材料级烧蚀试验和局部结构 烧蚀试验. 其中, 材料级烧蚀试验的目的是为了篮选 防热材料配方、考察防热材料的烧蚀性能; 局部结构 烧蚀试验的目的是为了验证返回器表面典型部位的 防热设计及烧蚀匹配性，通过典型部位的烧蚀试验， 验证整器的防热性能 ${ }^{[6,7]}$.

研制过程中，对烧蚀试验项目进行了梳理和统 筹，有针对性的选取关键部位，根据试验能力制定合 理的烧蚀试验条件, 同时试验与分析相结合, 综合评 估部件的防隔热性能以及几何不连续和材料不连续 所带来的影响. 同时, 针对跳跃式再入气动加热环境 特点, 对地面试验方法和技术开展了深入的研究.

1) 高焓长时间加热环境模拟试验方法

为了满足高焓、长时间加热试验需求，建立了叠 片式高焓电弧加热器, 气流总焓能够达到 $25 \mathrm{MJ} / \mathrm{kg}$, 运行时间可达 $2500 \mathrm{~s}$.

2) 二次再入气动加热环境的轨道模拟试验方法 针对飞行再入环境, 采用多台阶、中间停车的轨 道模拟试验方法开展防热结构的验证, 如图 7 所示.

\section{表 3 温度场分析}

\begin{tabular}{|c|c|}
\hline 分析类型 & 分析目的 \\
\hline 标称条件下的大面积防热层温度场分析 & 分析总加热量最大(含摄动)弹道条件下的背温水平 \\
\hline 故障条件下的大面积防热层温度场分析 & $\begin{array}{l}\text { 分析最大航程再入、最大摄动返回轨道条件下的背温水平 } \\
\text { 分析弹道式汳回轨道条件下的背温水平 }\end{array}$ \\
\hline 气动参数变化条件下大面积防热层温度场分析 & $\begin{array}{l}\text { 针对配平攻角变化所导致局部区域热环境变化进行背温评估计算 } \\
\text { 对弹抛天线舱体(含抛盖锁)防热设计进行分析验证 }\end{array}$ \\
\hline $\begin{array}{l}\text { (局部关键部位)热解材料温度场及三维热传导 } \\
\text { 温度场耦合影响分析 }\end{array}$ & $\begin{array}{l}\text { 对伞舱盖局部舱体结构(含弹射器)防热设计进行分析验证 } \\
\text { 对耐烧蚀天线结构(含透波窗)防热设计进行分析验证 } \\
\text { 对发动机舱盖(含导流管)防热设计进行分析验证 } \\
\text { 对操作窗口防热设计进行分析验证 }\end{array}$ \\
\hline 热气进入影响分析 & $\begin{array}{l}\text { 返回器结构为非密封结构, 存在安装缝隙和孔洞, 再入过程中热气进入会造成结构 } \\
\text { 度度高. 设计过程中, 对热气进入造成的影响进行了定量分析和试验验证 }\end{array}$ \\
\hline
\end{tabular}

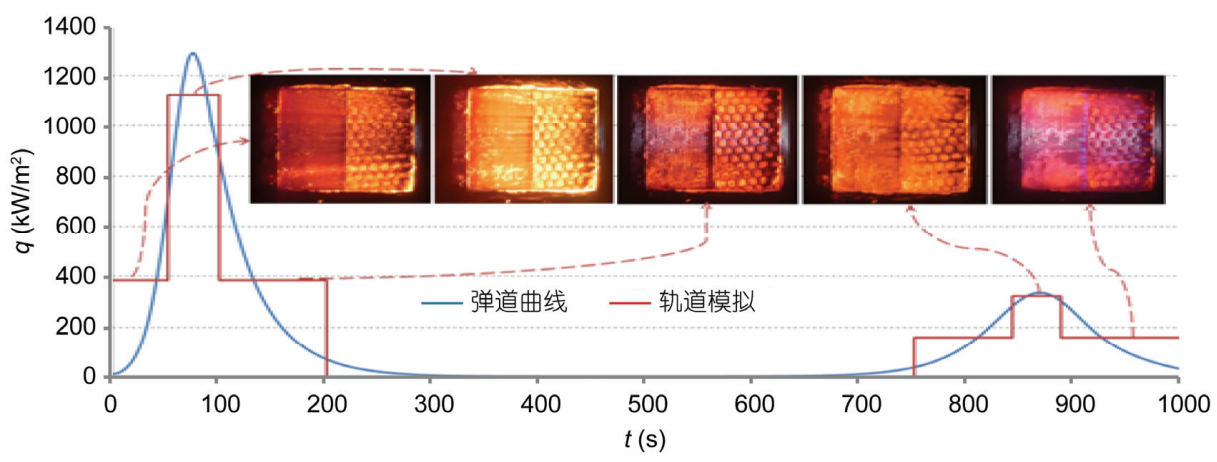

图 7 多台阶轨道模拟烧蚀试验示意图 
为了考察试验验证的有效性, 通过计算模型分 析了飞行再入加热环境条件下和烧蚀试验环境条件 下防热结构的热响应差异. 结果表明, 两种环境计算 得到的烧蚀后退量和背壁温度结果一致, 地面试验 正确有效.

\section{3) 大尺度防热结构考核试验模拟方法}

局部防热结构考核试验包括大底拐角、大底铁 管、伞舱盖、滚动发动机舱盖等, 试验难点体现在试 验模型尺度大, 试验状态高、时间长等方面. 根据模 型和状态的要求, 分别采用了大尺度均匀流场实现 技术、自由射流试验技术、亚声速导管绕流试验技术 等, 精确模拟了气动加热参数和边界层流动状态, 成 功完成了原来神舟飞船需要在国外才能进行的大尺 度结构模型烧蚀试验.

4) 防热材料性能考核试验模拟方法

针对防热结构验收, 制定了有效烧蚀热和烧蚀 热效率相结合的验收试验方法, 通过高、低两种热流 环境所得到的综合性能参数全面表征材料的耐烧蚀 性能和防隔热性能.

同时, 试验中采用超声速驻点试验技术模拟总 焓、热流密度和压力等参数. 通过试验件受试表面采 用球面外形，显著提高了烧蚀表面的热流分布均匀 性; 通过采用缠绕式水管冷却方式, 有效减少了侧壁 热流对模型内部的附加传热影响; 通过采用整体内 插式温度测试元件, 实现了小面积大纵向距离的内 部温度精确测量. 如图 8 所示.

\section{5 飞行试验结果及数据分析}

2014 年 10 月 24 日 2:00 时, 月地高速再入返回 飞行器于西昌卫星发射中心由 CZ-3C/G2 型运载火箭 发射升空送入绕月自由返回轨道. 10月 28 日 6:00 左 右, 分离监视相机拍摄的返回器照片如图 9 所示, 照

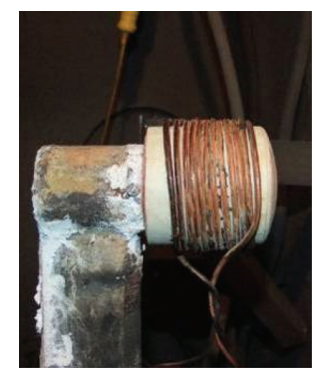

图 8 试验件在风洞中状态
片显示防热结构经历发射及空间环境后状态良好, 无任何异常.

2014 年 11 月 1 日 6:42, 返回器圆满完成了半弹 道跳跃式再入返回并安全着陆于内蒙古四子王旗, 再入弹道与预期吻合良好, 表明返回器烧蚀外形满 足气动和导航控制要求.

返回器落地状态见图 10(a)和(b), 防热系统的整 体烧蚀状态见图 10(a) (d).

防热系统的烧蚀状态与预期相符. 大底结构表 面平整，侧壁结构无明显的烧蚀后退，前端防热结构 无明显烧蚀, 返回器表面开孔、凹坑、缝隙、突起物 等烧蚀状态良好，不同防热材料间未出现烧蚀台阶， 材料的烧蚀匹配性良好.

安装在舱壁上的热电偶测温结果显示：整个再 入过程至落地, 返回器内壁温度满足总体指标要求.

伞舱盖弹射器和 2 个天线舱盖抛盖锁均按飞行 程序顺利弹抛, 说明火工品位置的局部防热设计满

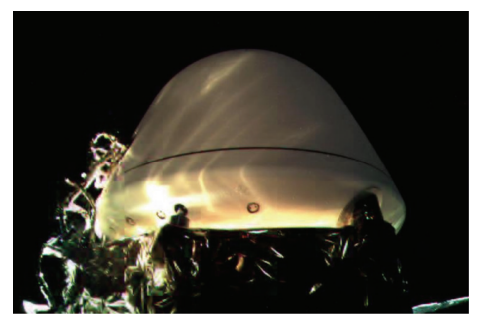

图 9 分离监视相机拍摄的返回器照片
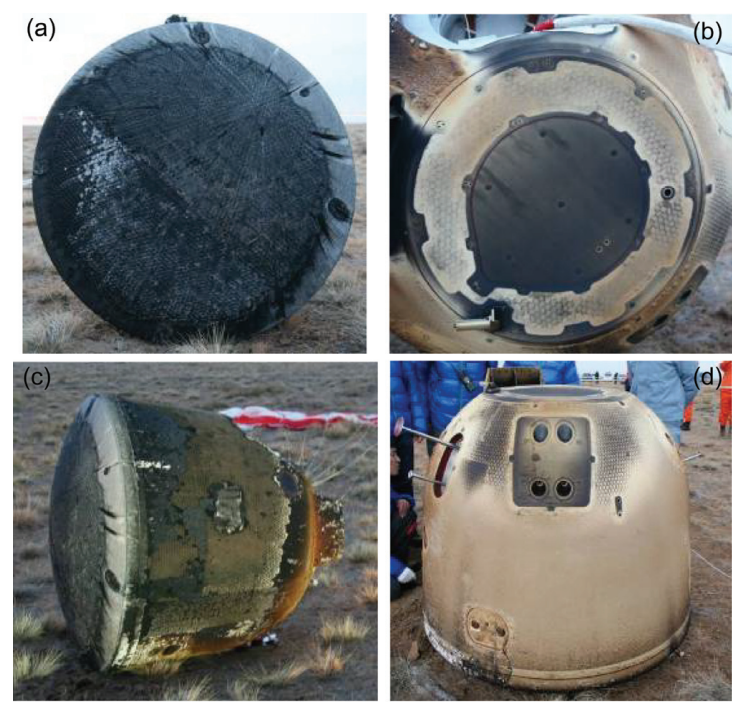

图 10 防热系统烧蚀状态

(a) 大底; (b) 前端; (c) 侧壁迎风面; (d) 侧壁背风面 
足要求.

在回收现场，采用激光三维扫描仪对大底结构 和侧壁结构迎风面的烧蚀外形进行了扫描, 返回器 结构烧蚀外形扫描结果见图 11.

数据分析显示: 大底结构有明显的烧蚀后退, 迎 风面拐角的烧蚀后退量最大达到了 $8.9 \mathrm{~mm}$, 背风面 拐角的烧蚀后退量最大达到了 $4.4 \mathrm{~mm}$; 侧壁结构无 烧蚀后退, 迎风面材料略有膨胀.

烧蚀状态与温度测试结果以及烧蚀后退量检测 结果表明: 飞行器防热系统 7 种材料的烧蚀匹配性 良好, 整器防热与局部防热设计合理, 防热系统安全 可靠.

为了校验分析模型, 对热敏电阻测点位置的温 度场和返回器对称面子午线烧蚀后退量进行了比对 计算.

图 12 给出了大底驻点区域计算温升曲线与热敏 电阻实测温升曲线的对比, 计算结果与实测结果吻 合得较好.

图 13 给出了返回器对称面子午线外轮廓计算预 测与返回后实测结果的对比, 防热设计选取的不同 热环境形成了对烧蚀后退的包络, 烧蚀后退量计算 结果与实测结果吻合较好.
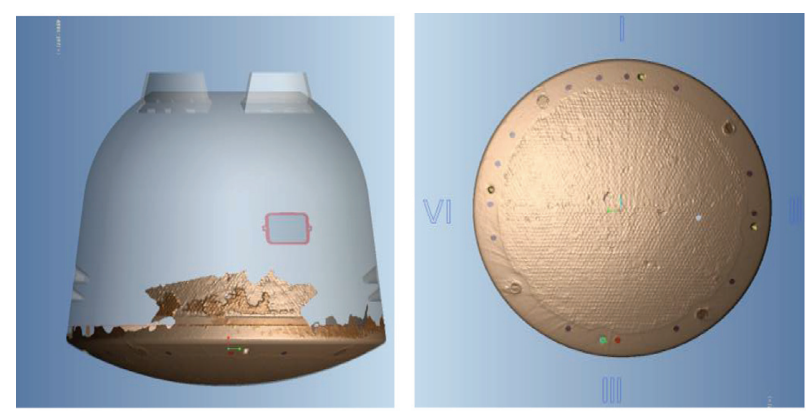

图 11 返回器结构烧蚀外形激光三维扫描结果

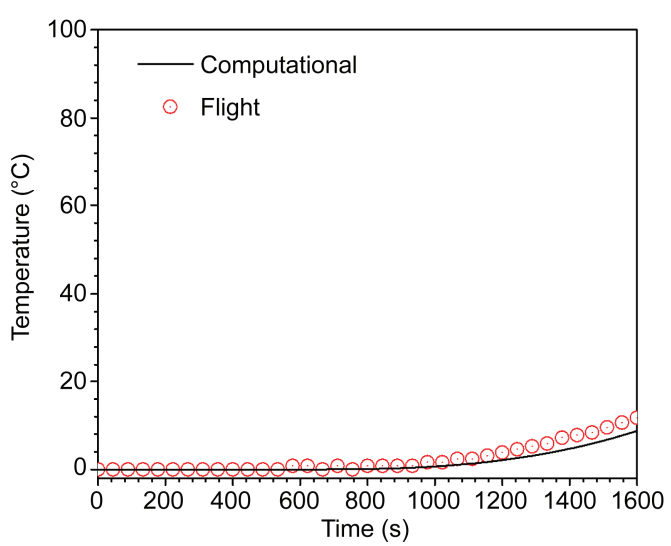

图 12 热敏电阻温度响应与计算结果对比

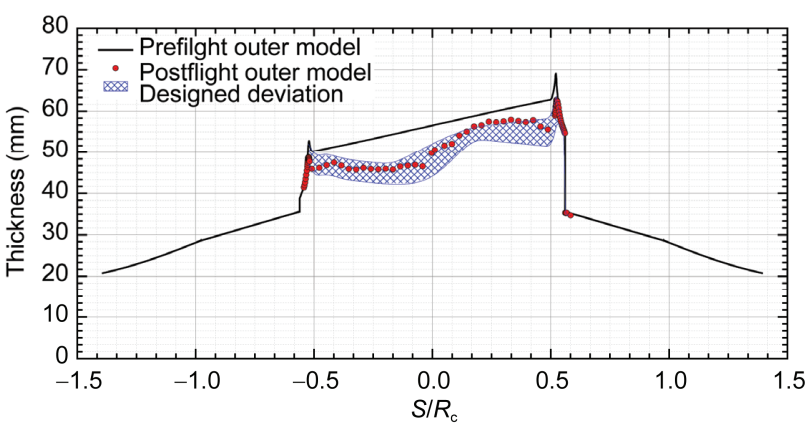

图 13 再入前后对称面子午线外轮廓实测与理论计算结果 对比

\section{6 结论}

针对月地高速再入返回的高焓、二次大气层再 入、高热流密度峰值与长加热时间耦合的气动加热环 境特点, 开展了全新的防热系统研制, 研制出了 7 种新 型碳硅复合低密度烧蚀防热材料, 提出了防热材料 分区域按需布置同时变厚度的轻量化设计方案, 建 立了防热系统分析模型，完成了地面试验验证. 经飞 行试验验证, 防热系统的实际性能与设计预期一致.

\section{参考文献}

1 王希季. 航天器进入与返回技术. 北京: 中国宇航出版社, 2009

2 陈烈民. 航天器结构与机构. 北京: 中国科学技术出版社, 2008

3 Hollos B R. Compression pad cavity heating augmentation on orion heat shield. J Thermophys Heat Tr, 2011, 25: 329-340

4 Marco Caporicci. European Crew and Logistics Vehicles for ISS and Exploration Missions. In: AIAA/CIRA 13th International Space Planes and Hypersonics Systems and Technologies Conference. Capua, 2005. 1-14

5 Schaefer J W, Flood D T, Reese J J, et al. Experimental and Analytical Evaluation of the Apollo Thermal Protection System under Simulated Reentry Conditions Part I. Aerotherm Final Report No 67-16. 1967 


\title{
Design and verification of the TPS of the circumlunar free return and reentry flight vehicle for the 3rd phase of Chinese lunar exploration program
}

\author{
DONG YanZhi ${ }^{1}$, LIU Feng ${ }^{1}$, YANG ChangHao ${ }^{1}$, ZHANG Gao $^{1}$, ZHAO JianShe $^{2}$, LUO XiaoGuang ${ }^{3}$,

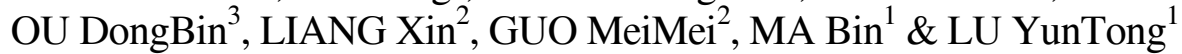 \\ ${ }^{1}$ Institute of Spacecraft System Engineering, China Academy of Space Technology, Beijing 100094, China; \\ ${ }^{2}$ Aerospace Research Institute of Materials \& Processing Technology, Beijing 100076, China; \\ ${ }^{3}$ China Academy of Aerospace Aerodynamics, Beijing 100074, China
}

The thermal protection system (TPS) of the high speed reentry vehicle is confronted with sever challenges, for the reentry environment has the characteristics such as high enthapy, twice rentry, the coupling of high heat flux and long time heating. This paper brings forward a design of the TPS, develops a new series of carbon-silicon based composite ablative materials, and establishes a simulation method of the entire ablation rate computed by carbon and silicon volume weighted, and an ablation test method for simulation of the whole reentry process through multiple steps and suspension condition. Based on the detailed analysis of test data, the TPS ensured the success of the task.

circumlunar free return and reentry, ablator, thermal protection system, design, verification

doi: $10.1360 / \mathrm{N} 092014-00468$ 